Macpherson, C. R. (1956). J.gen. Microbiol. 14, 520-526

\title{
Some Observations on the Antigenic Structure of Trichloroacetic Acid Extracts in Escherichia and the Paracolon Group
}

\author{
BY C. R. MACPHERSON* \\ Department of Pathology, University of Cape Town, \\ South Africa
}

SUMMARY: All the somatic antigens of 'smooth' type of some Escherichia and paracolon strains studied are not extracted by trichloroacetic acid (TCA), though they may be by boiling or by mechanical disruption of the cell.

The term' paracolon' is passing out of common use and is applied here descriptively rather than definitively. Some strains were encountered which were members of the family Enterobacteriaceae and resembled coliform organisms in their morphological and cultural characteristics; they were late, or non-lactosefermenters, and did not belong to Escherichia, Providence, Bethesda-Ballerup or other similar groups. Interest in the group was stimulated by an unusual case which has been reported elsewhere (Macpherson \& Exner-Baumann, 1950). At this time, investigators were pessimistic about the possibility of classifying the paracolon group by conventional serological methods (e.g. Stuart, Galton \& McGann, 1948; Mushin, 1949). The use of trichloroacetic acid (TCA) extracts as suggested by Boivin, Mesrobeanu, Magheru \& Magheru (1935) was considered. The success which had attended their employment in Pseudomonas (van den Ende, 1952) was felt to be encouraging and the technique was accordingly adopted.

Some success was obtained and the serological classification of biochemically homogeneous groups was possible. This classification was, of course, based on the somatic antigenic structure of the strains and could be confirmed and amplified by the use of ' $O$ ' and ' $H$ ' antisera (Macpherson, 1954). Anomalies were encountered, however, and it appeared that they were due either to the failure of the TCA to extract certain somatic antigens, or to the presence of antigens of 'envelope' type.

To confirm either of these possibilities, it was necessary to employ strains which shared labelled somatic or envelope antigens. By preparing antisera against such strains and then studying the cross-reactions obtained with TCA extracts, it should be evident whether some, all or no such antigens were being extracted. Since suitable paracolon strains were not available, Escherichia strains were obtained from Dr F. Kauffmann of Copenhagen.

It has been emphasized, almost since antigenic extracts were first studied, that they are not chemically homogeneous, and the occurrence of degradation

* Present address : Department of Medicine, Postgraduate Medical School, Ducane Road, London, W. 12. 
from full antigenicity is also well documented. However, such apparently capricious differentiation between presumably similar antigens, some being extracted and others not, does not appear to have been described before.

\section{METHODS}

The main antigens of the Escherichia strains are shown in Table 1. Cultures, after testing for purity, were dried by the method of Stamp (1947) and a fresh pellet used for each experiment. TCA extracts were prepared by the method of Boivin, Mesrobeanu \& Mesrobeanu (1933), but no attempt was made to purify the extracts or to concentrate them.

Table 1. Short antigenic formulae of Escherichia strains employed (Kauffmann's notation)

$\begin{array}{cccc}\text { Strain } & \text { O } & \text { K } & \text { H } \\ \text { O1 } & 1 & \text { L 1 } & 7 \\ \text { O2 } & 2 & \text { L 1 } & 4 \\ \text { H6 } & 2 & \text { L 1 } & 6 \\ \text { K7 } & 7 & \text { L7 } & 4 \\ \text { K 25 } & 8 & \text { B 25 } & 9 \\ \text { K48 } & 8 & \text { A48 } & 9\end{array}$

Antisera were prepared in rabbits. For paracolon, and Escherichias ' $H$ ' sera, overnight broth cultures were used, formalin having been added to a final concentration of $1 \%(\mathrm{v} / \mathrm{v})$. Saline suspensions of overnight agar cultures were used for the preparation of Escherichias ' $O K$ ' sera. Intravenous injections of $0 \cdot 25,0 \cdot 5,1 \cdot 0,1.5$ and $2 \cdot 0 \mathrm{ml}$. were given at 5-day intervals, and animals bled from the ear vein 7 days after the last injection. Strain K 48, which has an envelope antigen of ' $A$ ' type, was plated out and both non-capsulated and capsulated forms selected. Injected into separate rabbits, these gave rise to almost pure somatic and envelope antisera, labelled ' $\mathrm{A}-$ ' and 'A+' respectively. The titre of ' $\mathrm{O}$ ' and ' $\mathrm{H}$ ' antibodies was in the region of $1 / 2000 \mathrm{but}$, as is usual, the titre of ' $K$ ' antibodies was much lower.

Antisera were absorbed with the centrifuged deposit from an overnight broth culture. If living cultures were used to absorb an ' $\mathrm{OK}$ ' serum, pure ' $\mathrm{O}$ ' sera resulted (e.g. $\mathrm{K} 25^{\prime} \mathrm{O}$ ' serum). If the culture was heated at $100^{\circ}$ for $2 \frac{1}{2} \mathrm{hr}$. before absorption, or if a non-capsulated form was used, pure ' $K$ ' sera could be obtained (e.g. $\mathbf{K ~} 25$ ' $\mathrm{K}$ '). The proportion of serum to organisms was very important. The deposit of organisms was taken up in $1.5 \mathrm{ml}$. of serum which had been diluted $1 / 5$ with a $50 \%(\mathrm{v} / \mathrm{v})$ glycerol-saline mixture. After incubation at $37^{\circ}$ for $2 \mathrm{hr}$. and overnight at $2^{\circ}$ the mixture was centrifuged and the supernatant fluid removed. Varying the relative amounts within fairly narrow limits gave rise to frequent anomalous results. Glycerol-saline had to be used for the dilutions since use of a fluid of lower viscosity made it impossible to layer the TCA extracts on top of the serum for the ring precipitation tests which were used throughout. 
Agglutination tests were by the tube method, equal parts of serum and suspensions being used. $O$ antigens were incubated at $37^{\circ}$ for $18 \mathrm{hr}$., $\mathrm{L}$ and $\mathrm{B}$ antigens for $2 \mathrm{hr}$. at $37^{\circ}$ and $20 \mathrm{hr}$. at room temperature, $A$ antigens for $20 \mathrm{hr}$. at $50^{\circ}$ and $\mathrm{H}$ antigens for $2 \mathrm{hr}$. at $50^{\circ}$ and then overnight at room temperature. All tests were read macroscopically.

Mechanical disintegration of cultures was by the technique of Salton \& Horne (1951), using glass ballotini in a Mickle disintegrator followed by centrifugation at 10,000 r.p.m. for $15 \mathrm{~min}$. to sediment the bacterial debris.

\section{RESULTS}

TCA extracts of the strains shown in Table 1 were tested against the antisera prepared from these strains, with the results shown in Table 2 . It will be seen that cross-reaction occurs between the extracts from strains $\mathrm{O} 2$ and $\mathrm{H6}$, which share $\mathrm{O}$ antigen 2, but that there is no cross-reaction between strains $K 25$ and $K 48$, which share $O$ antigen 8. There is no evidence that any envelope or flagellar antigen is present in the extracts.

\section{Table 2. Reactions between TCA extracts and antisera of strains in Table 1}

TCA extracts of strains

$\begin{array}{lccccccc}\text { Antisera } & \text { O1 } & \text { O2 } & \text { H6 } & \text { K7 } & \text { K25 } & \text { K48A+ } & \text { K48A- } \\ \text { O1 } & ++ & - & - & - & - & - & - \\ \text { O2 } & - & ++ & + & - & - & - & - \\ \text { H6 } & - & + & ++ & - & - & - & - \\ \text { K7 } & - & - & - & ++ & - & - & - \\ \text { K25 } & - & - & - & - & ++ & - & - \\ \text { K48A+ } & - & - & - & - & - & ++ & \pm \\ \text { K48A } & - & - & - & - & - & ++ & ++\end{array}$

$++=$ immediate, marked ring of precipitation; $+=$ immediate, but only slight, ring of precipitation; $\pm=$ slight ring, taking more than $5 \mathrm{~min}$. to develop; $-=$ no ring of precipitation after 45 min.

Since these latter two strains should, theoretically, have cross-reacted, agglutination tests were put up, using both the ordinary $\mathrm{K} 25$ ' $\mathrm{OK}$ ' serum and absorbed sera. ' $O K$ ' sera were absorbed both with living and with heated suspensions of their homologous strains to produce pure ' $O$ ' and ' $K$ ' sera. It is evident that there is marked cross-agglutination due to sharing of $\mathrm{O}$ antigen 8 (Table 3).

A further method of investigating this anomaly was suggested by findings in the earlier studies with paracolon strains. The polysaccharide of the TCA extracts had been found to be very resistant to heating at $100^{\circ}$ or $120^{\circ}$, no detectable, or minimal fall in titre resulting. If, however, the cell suspension was heated before extracting with TCA, the extract either failed to precipitate, or reacted very feebly with homologous serum. The reason for this was not that the polysaccharide was being altered or destroyed within the body of the organism, but that it was being extracted by the heating process, regardless of the type of fluid in which the organisms were suspended. A number of experi- 
ments designed to prove this point did so unequivocally, and a representative experiment is described below.

By serial subculture, with agitation, a heavily turbid culture late in the logarithmic phase was prepared, and was divided into four equal parts. The first part was extracted with TCA in the usual way. Part 2 was boiled for $1 \mathrm{hr}$. and centrifuged. The supernatant fluid was retained and the pellet extracted

Table 3. Reactions between $K 25$ and $K 48$ antisera, and heated and unheated agglutinable suspensions

\begin{tabular}{lcccc} 
& \multicolumn{4}{c}{ Suspensions } \\
Antisera & K48A+ & Heated & Heated & K48A+ \\
K48 pure 'O' & - & ++ & K25 & K25 \\
K48 pure ' $K$ ' & + & - & ++ & \pm \\
K25 'OK' serum & - & ++ & - & - \\
K25 pure 'O' & - & ++ & ++ & + \\
K25 pure ' $K$ ' & - & - & ++ & \pm
\end{tabular}

Preparation and notation of absorbed sera-see 'Methods'. Precipitation reactions-as for Table 2. Agglutination reactions: $++=$ agglutination at a dilution of $1 / 200$ or higher; $+=$ no agglutination above $1 / 20$ dilution; $\pm=$ no agglutination above $1 / 2$ dilution; $-=$ no agglutination at any dilution.

with TCA. Part 3 was also boiled for $1 \mathrm{hr}$. and centrifuged. The supernatant fluid was discarded and the pellet was mechanically disintegrated. After further centrifugation, the supernatant fluid was retained and the pellet extracted with TCA. Part 4 was mechanically disintegrated (without prior boiling) and centrifuged. The supernatant fluid was retained and the pellet extracted with TCA. All these fluids were then tested against homologous serum, with the results shown in Table 4. It is evident that boiling removes practically all the

Table 4. Effect of heat and/or mechanical disintegration prior to TCA extraction.

Type of fluid tested

Normal TCA extract

SNF after boiling culture for $1 \mathrm{hr}$.

TCA extract after boiling culture

SNF after mechanical disintegration, following boiling

TCA extract after boiling and mechanical disintegration

SNF after mechanical disintegration only

TCA extract after mechanical disintegration only

SNF after standing at room temperature for $6 \mathrm{hr}$.
Homologous

serum

$+$

$+$

$\pm$

$\pm$

$++$

-

SNF = supernatant fluid pipetted off after centrifugation. Precipitation reactions-as for Table 2.

TCA-extractable and mechanically-extractable material, while mechanical disintegration removes all the TCA-extractable material. The presence, and survival, of precipitable material in the various fluids shows that in each case the process is one of extraction, and not of destruction.

One interesting finding was that the antibody-binding power of a control culture was not detectably different before and after boiling. 
An obvious possibility, in view of the above findings, was that in preparation, by heating, of O-agglutinable suspensions in Escherichia strains possessing an envelope antigen of ' $L$ ' type (Kauffmann, 1951), the envelope antigen might be completely extracted into the fluid, rather than being destroyed. However, application of the above technique to Escherichia strains K 25 and K 48, using the absorbed sera prepared for the first experiment, showed that this was not the case (Table 5 ). This table also shows that $\mathrm{O}$ antigen 8 is extracted by heating and that it is then freely cross-precipitated by the heterologous serum. Titration of these 'heat-extracts' with heterologous and homologous serum gave a much lower titre in the former, indicating that $O$ antigen 8 can form only a small part of the precipitating material.

Table 5. Precipitation reactions between $K 25$ and $K 48$ absorbed sera, and supernatant fluids from heated cultures

$\begin{array}{lccc}\text { Antisera } & \overbrace{\mathbf{K 4 8 A}+}^{\text {Supernatant fluids from heated cultures }} & \mathbf{K 4 8 A}- & \mathbf{K 2 5} \\ \text { K48, pure 'O' } & ++ & ++ & ++ \\ \text { K48, pure 'K' } & - & - & - \\ \text { K25, pure 'O' } & ++ & ++ & ++ \\ \text { K25, pure ' } K \text { ' } & - & - & -\end{array}$

Absorbed sera-for preparation and notation, see under 'Methods'. Precipitation reactions-as for Table 2 .

To summarize, it could be shown that in these two Escherichia strains, $O$ antigen 8 was extractable by heating and mechanical disintegration but not by TCA, while the other somatic antigens were freely extractable by all three methods. Neither heat nor TCA extracted antigens of envelope type.

Confirmation was thus obtained of the hypothesis which had been advanced to explain the anomaly found in the earlier paracolon studies. The anomaly was that mirror absorption tests had shown the TCA extracts of a group of 6 strains to be identical. Agglutination tests showed that the first five members of the group were very similar to each other but shared only minor antigens with the sixth member, cross-agglutinating only at dilutions of $1 / 20$ or less (Table 6).

Table 6. Comparison of agglutination and precipitation reactions in a group of 6 paracolon strains, using absorbed and unabsorbed sera

\begin{tabular}{lcccc}
\multicolumn{1}{c}{ Antisera } & $\overbrace{1}^{\text {Agglutinating suspensions }}$ & Group & $\overbrace{1}^{2}$ & Group \\
1 & $1 / 2000$ & $1 / 20$ & ++ & ++ \\
Group & - & $1 / 2000$ & ++ & ++ \\
$1-1$ & - & - & - & - \\
1-Group & $1 / 2000$ & - & - & - \\
Group-Group & - & - & - & - \\
Group-1 & - & $1 / 2000$ & - & -
\end{tabular}

'Group' indicates any member of the subgroup of 5 strains-all reacted similarly. ' 1 ' indicates the sixth member of the group. Agglutination tests-as for Table 3. Precipitation tests-as for Table 2. '1-group' indicates that serum 1 has been absorbed by a suspension of one or other strain in the subgroup of 5 strains. 
From this table it is evident that however minor an agglutinogen this antigen may be, it is the only one which is extracted in all six strains. This is proved by the ability of any strain to exhaust the precipitins (as distinct from the agglutinins) from any heterologous serum.

A similar anomaly found in another group of paracolon strains may be explained by the fact that the TCA extraction method was not sufficiently sensitive. The antigen was present in minute amounts, being just detectable by mechanical disintegration but not by heat-extraction.

\section{DISCUSSION}

The most important; finding is' that TCA may fail to extract one or more of the somatic antigens in an organism while extracting the rest quite satisfactorily; no explanation for this phenomenon can be offered. It constitutes a strong argument against the use of TCA extracts for serological classification, unless the results are controlled by other methods. It would not, however, invalidate the use of TCA extracts of proven antigenic structure for rapid screening of large numbers of sera.

In both the Escherichia and paracolon groups, marked discrepancies were found between the antigens in question, as judged by the precipitation and agglutination tests, and it is interesting to speculate how much of this can be explained by a superficial or deep situation in the wall of the organism. The most reasonable explanation of the agglutinogenic dominance of Escherichia $O$ antigen 8 , which is present in only small amount in the extracts, would seem to be that it is superficially situated.

The fact that heat-extraction of antigens produces no detectable diminution in antibody-binding capacity would suggest that comparatively little of the available antigen is normally concerned in this function. However, heatextraction may offer an explanation for Kauffmann's observation that 'when working with a non-flagellated acapsular strain, a stronger $\mathbf{O}$ serum is obtained if the strain is killed with $0.5 \%$ formalin and not by heating'.

The failure of TCA to extract the envelope antigens of these Escherichia strains is interesting, contrasting as it does with TCA's known ability to extract the $\mathrm{Vi}$ antigen of Salmonella typhi (Combiesco, Combiesco \& Soru, 1937; Boivin \& Mesrobeanu, 1938).

Since decisions on relationships between strains, and even groups, of bacteria are often influenced by the dominance of one or other antigen as an agglutinogen, it seems possible that this lack of correlation between the results in the precipitin and agglutinin tests may be of taxonomic significance.

Grateful acknowledgement is made of permission to publish the above information which was contained in a thesis accepted in part fulfilment of the requirements for the degree of M.D. (Pathology) at the University of Cape Town. I am also grateful to members of the Department of Pathology for helpful eriticism, and to Dr F. Kauffmann for providing the Escherichia cultures. 


\section{REFERENCES}

Boivin, A., Mesrobeanu, I. \& Mesrobeanu, L. (1933). Technique pour la préparation des polysaccharides microbiens spécifiques. C.R. Soc. Biol., Paris, 113, 490.

Borvin, A. \& Mesnobeanu, L. (1938). Recherches sur les antigènes somatiques du bacille typhique. Sur la nature chimique des antigènes ' $O$ ' et 'Vi', C.R. Soc. Biol., Paris, 128, 5.

Boivin, A., Mesrobeanu, L., Magheru, G. \& Magheru, A. (1935). Recherches biologiques et chimiques sur l'antigène somatique 'complet' renfermé dans quelques colibacilles. C.R. Soc. Biol., Paris, 120, 1276.

Сombiesco, D., Combiesco, C. \& Soru, E. (1937). Quelques propriétés physicochimiques, biologiques et sérologiques des antigènes glucido-lipidiques des bacilles typhiques. C.R. Soc. Biol., Paris, 126, 1081.

Kauffmann, F. (1951). Enterobacteriaceae, 1st ed. Copenhagen: Ejnar Munksgaard.

Macpinerson, C. R. (1954). A Nerw Approach to the Serological Classification of Paracolons. M.D. thesis, University of Cape Town.

Macpherson, C. R. \& Exner-Baumann, W.-F. (1950). Paracolon bacillus septicaemia: A fatal case with multiple necrotic foci in the liver. S. Afr. J. clin. Sci. $1,172$.

Mushin, R. (1949). Studies on paracolon bacilli. Aust. J. exp. Biol. med. Sci. 27, 543.

Salton, M. R. J. \& Horne, R. W. (1951). Studies of the bacterial wall. II. Methods of preparation and some properties of cell walls. Biochim. biophys. Acta, 7, 17 .

Stamp, Lond (1947). The preservation of bacteria by drying. J.gen. Microbiol. 1, 251.

Stuart, C. A., Galton, M. M. \& McGanN, V. (1948). Antigenic relationships of 765 Paracolobactrum intermediate cultures. J. Bact. 56, 411.

VAN DEN ENDE, M. (1952). Observations on the antigenic structure of Pseudomonas aeruginosa. J. Hyg., Camb. 50, 405.

(Received 20 September 1955) 